\title{
DISCUSSION
}

\section{Calibrations of a high-suction tensiometer}

\author{
S. D. N. LOUREnÇO, D. GAllipoli, D. G. TOlL, C. E. AUGARde, F. D. EVAnS \\ and G. M. MEDERO (2008). Géotechnique 58, No. 8, 659-668
}

\section{E. C. Leong and H. Rahardjo, Nanyang Technological University, Singapore}

L. He, AMEC Geomatrix, Newport Beach, USA

The authors have presented very careful experiments to evaluate the accuracy of calibrations of a high-suction tensiometer. Indeed, for a given high-suction tensiometer design and method of saturation, the accuracy of the calibration dictates its performance. There is still no consensus on: (a) the dimensions of the water reservoir beneath the high air-entry ceramic disc, though it is widely accepted that it should be 'small'; (2) the thickness of the high airentry ceramic disc; or (3) saturation procedure (Rahardjo \& Leong, 2006). For example, Ridley \& Burland (1993) used a water reservoir of $3 \mathrm{~mm}^{3}$, a 15 bar ceramic disc of $3.5 \mathrm{~mm}$ thick and saturation under a pressure of $6000 \mathrm{kPa}$; Guan \& Fredlund (1997) used a water reservoir of 0.7$3.5 \mathrm{~mm}^{3}$, a 15 bar ceramic disc $3-3.15 \mathrm{~mm}$ thick and a saturation procedure of 6 cycles at $12000 \mathrm{kPa}$ for $1 \mathrm{~h}$ and $-85 \mathrm{kPa}$ for $1 \mathrm{~h}$; and Lourenço et al. (2006) used a water reservoir of $10 \mathrm{~mm}^{3}$, a 15 bar ceramic disc $10 \mathrm{~mm}$ thick, and a saturation procedure consisting in first saturating the ceramic disc under vacuum, followed by a pressure of $800 \mathrm{kPa}$ for $48-72 \mathrm{~h}$. In the above literature and the authors' work, the maximum measurable suction appears to be between 1000 and $1250 \mathrm{kPa}$. One would expect that the maximum measurable suction for a fully saturated highsuction tensiometer should be close to the air-entry value of the ceramic disc used. The writers could not understand why the authors mentioned a maximum measurable suction of $2 \mathrm{MPa}$. To the writers' knowledge, the highest air-entry value available for a ceramic disc is 15 bar, meaning that one could presumably measure a maximum suction of about $1500 \mathrm{kPa}$ using a high-suction tensiometer. In the writers' experience, for a high-suction tensiometer with a 5 bar ceramic disc the maximum measurable suction is only slightly above $500 \mathrm{kPa}$, as expected (He et al., 2006). This indicates that the design and saturation process limits the maximum measurable suction of the high-suction tensiometer fitted with a 15 bar ceramic disc. Therefore the problem of accuracy of the high-suction tensiometer should be addressed in totality.

The writers fully agree with the authors that the tensiometer should be calibrated using a method that resembles the conditions of use. Therefore there will be a fundamental difference if the tensiometer is used in a laboratory set-up as an on-specimen tensiometer or as a stand-alone tensiometer. In laboratory tests, where the axis-translation technique is frequently applied, the readings of the tensiometer are still in the positive pressure range (Meilani et al., 2002), whereas as a stand-alone tensiometer the readings will be in the negative range. In the former, calibrating the tensiometer in the positive range is sufficient.

One of the tenets when selecting the pressure transducer to be used in the high-suction tensiometer is to use a highercapacity pressure transducer so that the flexing in the opposite direction will be only a fraction of the full deflection under the maximum compression pressure, therefore reducing the error using a calibration line extrapolated from the compression range. This aspect was not addressed in the paper.

Preparing soil specimens using isotropic unloading introduces an uncertainty on the actual matrix suction created in the soil specimens. In fact, using soil specimens where suction is induced by unloading is always difficult, as evidenced in past researches where such soil specimens were used for calibration purposes (Leong et al., 2002). An alternative method of checking the extrapolation using the axis-translation technique is to use the set-up shown in Fig. 15 , where the high-suction tensiometer is fixed at the bottom of an air pressure chamber. The procedure involves placing an unsaturated soil specimen on the high-suction tensiometer and closing the pressure chamber. The air pressure in the pressure chamber is then increased and adjusted until the high-suction tensiometer reading is $0 \mathrm{kPa}$. The matric suction of the soil specimen is therefore equal to the applied air pressure. Thereafter the air pressure is reduced slowly to zero, and the response of the high-suction tensiometer is observed.

\section{Authors' reply}

The authors wish to thank the discussers for their interest in the paper, and for their useful remarks. The authors are aware of the high-quality work undertaken by the discussers over recent years, and welcome exchange of experience on this challenging topic.

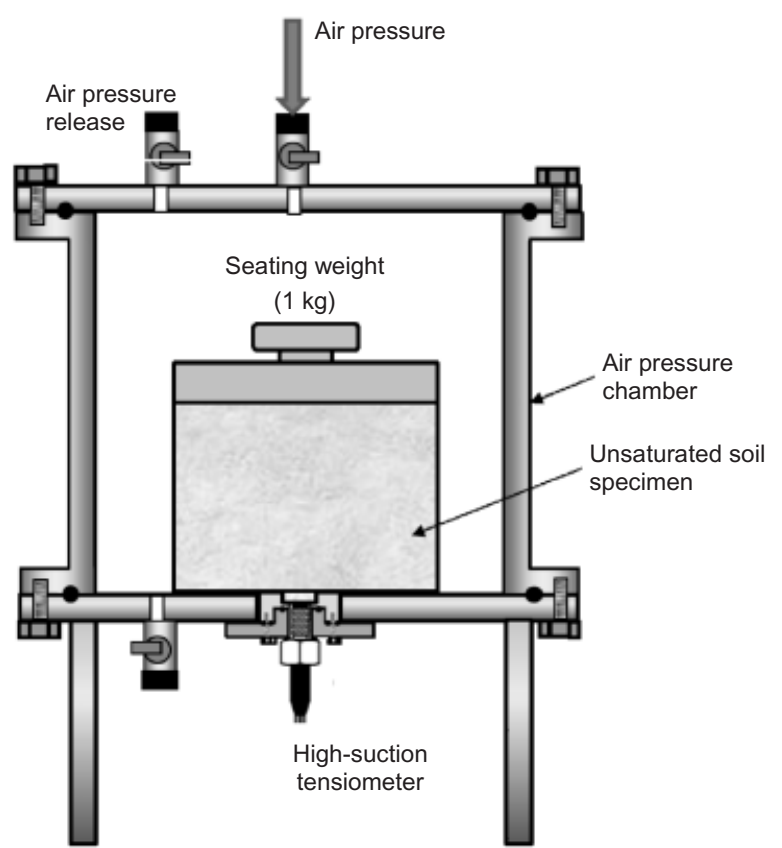

Fig. 15. Set-up for checking the accuracy of a high-suction tensiometer using extrapolated pressure calibration in the negative range 
In analysing measurement limits of high-suction tensiometers, it is important to distinguish between the two distinct physical processes of air blowing through the ceramic and water cavitation. For the tests presented in the paper, it is likely that the value of the maximum measured suction was dictated by cavitation inside the probe rather than by air blowing through the ceramic, even when the maximum measured suction was well beyond the nominal blow-through limit of the ceramic. The actual blow-through pressures of commercial high air entry value ceramics can be considerably higher than the nominal limits rated by manufacturers. Nominal limits are often taken to coincide with the lowest achievable blow-through pressure, and hence most commercial ceramics will be able to sustain higher suctions than the rated values. For example, Toll (1988) measured the blow-through pressure for a $500 \mathrm{kPa}$ rated ceramic and found values that varied between $550 \mathrm{kPa}$ and $700 \mathrm{kPa}$. Maswoswe (1985) reported a blow-through pressure of $900 \mathrm{kPa}$ for a ceramic with a nominal limit of $500 \mathrm{kPa}$, and Taylor (2004) found that the blow-through pressure for the $500 \mathrm{kPa}$ rated ceramics used at Durham University can exceed $640 \mathrm{kPa}$.

Moreover, when taking suction measurements on finegrained soil samples, ceramic blow-through will occur only if the measured suction exceeds the air entry value of the sample. Therefore, for measurements taken on saturated fine-grained soils with air entry values significantly higher than the ceramic blow-through pressure, the value of the maximum measured suction is likely to be dictated by cavitation inside the probe rather than by ceramic blowthrough.

The authors agree with the discussers that the performance of high-suction tensiometers is significantly influenced by the water reservoir dimension, ceramic thickness and saturation procedure. However, the analysis of such factors requires a detailed programme of investigation, which goes beyond the scope of the paper. These issues will be partly addressed in a forthcoming publication, which will also provide a possible explanation of why some of the tensiometers used for this research measured a maximum suction up to $2000 \mathrm{kPa}$, well beyond the ceramic blow-through pressure of $1500 \mathrm{kPa}$.

The authors agree with the discussers about the importance of selecting appropriate pressure transducers in the design of high-suction tensiometers, especially if the transducer deflection is not symmetrical when subjected to pressure differential of opposite sign. In such cases, as suggested by the discussers, the error due to the extrapolation of the calibration from the positive to the negative pressure range might be minimised by limiting the measurement span to a small fraction of the full transducer deflection. Note, however, that the use of large-capacity transducers can compromise accuracy of measurements at low suctions, given that the precision of commercial transducers is often rated as a fixed percentage of the full-scale output.

The authors welcome the set-up shown by the discussers in Figure 15 for checking the accuracy of the calibration extrapolation from the positive to the negative pressure range. This set-up is based on the use of the axis-translation technique, similar to the procedure described in the paper. However, while the authors used the axis-translation technique in a triaxial cell, the discussers propose a modified cell where the high air entry value ceramic is absent, and the sample water content, rather than the sample suction, is controlled during measurement. The set-up proposed by the discussers overcomes the difficulties caused by inflow of water from the saturated ceramic into the sample when air pressure is reduced to the atmospheric value, and therefore avoids the consequent suction drop observed during the tests reported in the paper. The authors would suggest only that the gap around the sample be maintained as small as possible, and that air pressure be raised relatively rapidly to prevent drying by evaporation. A small disadvantage of the procedure suggested by the discussers is given by the fact that measurements of different suction levels will require preparation of different samples at variable water content to be placed in turn inside the measurement cell. This might require longer testing times compared with the procedure presented in the paper, where a single sample can instead be used for measurements at different suction levels imposed inside the triaxial cell.

\section{REFERENCES}

He, L., Leong, E. C. \& Algamal, A. (2006). A miniature tensiometer for measurement of high matric suction. Proc. 4th Int. Conf. on Unsaturated Soils, Carefree, AZ 2, 1897-1907.

Leong, E. C., He, L. \& Rahardjo, H. (2002). Factors affecting the filter paper method for total and matric suction measurements. Geotech. Test. J. 25, No. 3, 321-332.

Maswoswe, J. (1985). Stress path for a compacted soil during collapse due to wetting. $\mathrm{PhD}$ thesis, Imperial College, London.

Rahardjo, H. \& Leong, E. C. (2006). Suction measurements. Proc. 4th Int. Conf. on Unsaturated Soils, Carefree, AZ 1, 81-104.

Taylor, R. (2004). Use of an air-trap pump system to investigate the effect of soil suction on air diffusion through high air entry value disks. MEng final year dissertation, Durham University.

Toll, D. G. (1988). The behaviour of unsaturated compacted naturally occurring gravel. $\mathrm{PhD}$ thesis, Imperial College, London. 